\title{
Heat Transfer and Flow Analysis in Loop Heat Pipe with Multiple Evaporators Using Network Model
}

\author{
Shigeki Hirasawa, Tsuyoshi Kawanami, and Katsuaki Shirai \\ Department of Mechanical Engineering, Kobe University, 1-1 Rokkodai, Nadaku, Kobe, Hyogo 657-8501, Japan
}

\begin{abstract}
Thermal performance of a loop heat pipe with two evaporators and two condensers was examined using a lumped network model analysis. Thermosyphon-type vertical loop heat pipe and capillary-pump-type horizontal loop heat pipe were calculated by examining the change of heating rate of two evaporators. Calculation results showed that the vapor and liquid flow rates in the loop heat pipe and the thermal conductance of the heat pipe changed significantly depending on the distribution ratio of the heating rate of the multiple evaporators. The thermal performance of the vertical loop heat pipe with two evaporators was also examined and experimental results of flow direction and thermal conductance of the heat pipe agreed with the analytical results. The lumped network model analysis is therefore considered accurate and preferable for the practical design of a loop heat pipe with multiple evaporators.
\end{abstract}

Key words: Loop heat pipe, multiple evaporators, thermal conductance, network model analysis, two phase flow.

\section{Introduction}

Loop heat pipe is an efficient heat transfer device that utilizes the evaporation and condensation of a working fluid and the circulation of the fluid by capillary force in a wick or gravity force. It is a well-known thermal management device. Loop heat pipes have been used in various applications such as cooling systems for high-power electronic devices [1] and solar thermal collector systems [2]. Loop heat pipe with multiple evaporators has the advantage of design flexibility for the cooling systems of many heating devices and it has been used for spacecraft applications $[3,4]$.

Various works on the heat transfer performance of loop heat pipes have been reported. Kaya and Goldak [5] reported the boiling limit of loop heat pipe obtained from the analysis of heat and mass transfer in a porous wick in the evaporator of loop heat pipe. Mass, momentum, and energy equations were solved using a finite element method. Figus et al. [6] reported the analytical results of phase change phenomena in a

Corresponding author: Shigeki Hirasawa, professor, research fields: thermo-fluid control and heat transfer in equipment. porous wick of a loop heat pipe using the pore network model. The pore network model was a thermo-fluid numerical simulation method in which the calculation region was modeled by a fine network with many pores and throats. Governing equations at the pores and throats were numerically solved iteratively. Jesuthasan and Baliga [7] reported the steady thermal performance of a horizontal loop heat pipe with a flat-evaporator for four working fluids obtained from analysis using a lumped network model. The lumped network model analysis is a simple calculation method using a rather small number of node points and has been used widely in heat transfer and flow analyses [8, 9]. Jesuthasan and Baliga [7] used assumption of the stratified-wavy flow or annular flow for the two-phase flow pattern and the same flow direction of the liquid and vapor in the tube. The calculation parameters were the total mass flow rate and flow quality in the two-phase flow. Five nodes were used in their analysis and an iteration method was utilized to solve governing equations. Bai et al. [10] reported the analytical results of the startup behavior of a horizontal loop heat pipe driven by a capillary force in a porous wick using the lumped network model. They used the assumption of the uniform two-phase 
flow pattern. The calculation parameters were the total mass flow rate and enthalpy in the two-phase flow. About 20 nodes were used in their analysis and an implicit iteration technique was utilized to solve governing equations at each time step. Goncharov et al. [11] reported the experimental results of the thermal performance of loop heat pipes with two and three evaporators. Nagano and $\mathrm{Ku}$ [12] reported the experimental results of thermal performance and capillary limit of heat transfer of a loop heat pipe with two evaporators by changing heat loads of evaporators and inclination of the heat pipe. Ku et al. [3, 4] reported the analytical and experimental results of the steady and transient thermal performance of a loop heat pipe with two evaporators and two condensers. Energy equations at about 1,300 nodes were solved using a finite-difference method. Advantages of the loop heat pipe with multiple evaporators in comparison with a single loop heat pipe were reported.

In order to design the optimal loop heat pipe for practical use, it is indispensable to develop a useful simulation tool to calculate heat transfer performance according to the conditions of applications. The lumped network model analysis is a simple calculation method and computation time is less than $1 / 100$ compared with that of a CFD simulation. We think the lumped network model analysis is useful for the practical design due to the simplicity. In this work, the thermal performance of a loop heat pipe with two evaporators and two condensers was studied using the lumped network model analysis and experiments.

\section{Analytical Model}

Fig. 1 shows the model of a thermosyphon-type loop heat pipe with two evaporators and two condensers. In the thermosyphon-type loop heat pipe, the working fluid circulates with the gravity force and there is no wick material in the tube. Our loop heat pipe had a center transport line of a horizontal tube to make two sub-loops to enhance flexibility of fluid flow in the loop. Two evaporators were placed at the lower part of the heat pipe and two condensers were placed at the upper part. The heating rate of both evaporators was changed to be different and the same. The vapor generated in the evaporators basically goes up and the condensed liquid goes down from the condenser by the gravity force. However, interaction between the vapor flow and the liquid flow causes flow in the same direction when the vapor and liquid flow rates become the flooding condition of two-phase flow [13].

The lumped network method was used to simulate the thermal performance of a loop heat pipe. In this method, the loop heat pipe is divided into a small number of nodes and elements. Fig. 2 shows the network model corresponding to the loop heat pipe shown in Fig. 1. The pressure $P_{\mathrm{i}}$ at $i$ node and the vapor and liquid flow rates $G_{\mathrm{vji}}$ and $G_{\mathrm{lji}}(\mathrm{kg} / \mathrm{s})$ from $j$ element into $i$ node were defined at each node. Average fluid and wall temperatures $T_{\mathrm{fj}}$ and $T_{\mathrm{wj}}$ in $j$ element were defined at each element. Governing equations including mass, momentum, and energy equations were established at each node and element.

Heat transfer rate $Q_{\mathrm{j}}(\mathrm{W})$ in $j$ element from wall to fluid is calculated as follows.

$$
Q_{j}=h_{j} A_{j}\left(T_{w j}-T_{f j}\right)
$$

where $h_{\mathrm{j}}$ and $A_{\mathrm{j}}$ are the inside heat transfer coefficient $\left(\mathrm{W} / \mathrm{m}^{2} \mathrm{~K}\right)$ and the area of the $j$ element. The wall temperature $T_{\mathrm{wj}}$ of the tube was obtained using the

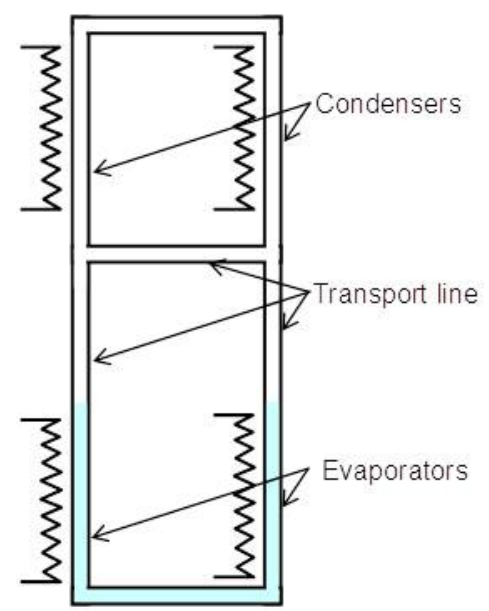

Fig. 1 Calculation model of thermosyphon-type loop heat pipe with two evaporators. 


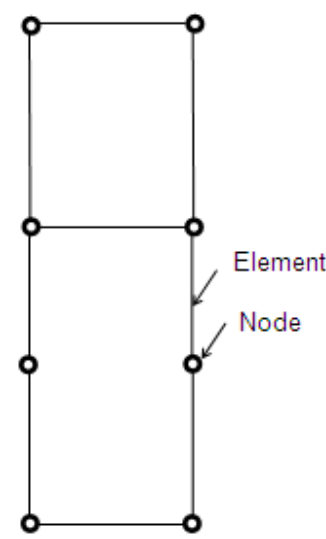

Fig. 2 Network model of loop heat pipe.

outside heat transfer coefficient, the surrounding air temperature, and the heating rate of the evaporator element. The inside heat transfer coefficient $h_{\mathrm{j}}$ was obtained using the equations for two-phase condensation heat transfer coefficient $h_{\text {ctp }}$ [14] for the condenser and transport line elements and using the two-phase evaporation heat transfer coefficient $h_{\mathrm{btp}}$ [15] for the evaporator element as follows.

$$
\begin{gathered}
h_{c t p}=h_{l}\left\{(1-x)^{0.8}+3.8 x^{0.76}(1-x)^{0.04}\left(P_{s} / P_{c r i}\right)^{-0.38}\right\} \\
h_{b t p}=h_{l 0} 0.739\left\{10^{4}\left(q / G_{t} L\right)+1.5 X_{t t}^{-2 / 3}\right\}
\end{gathered}
$$

where, $h_{1}$ is the convective heat transfer coefficient for only liquid flow rate, $x$ is the flow quality that is the ratio of the vapor mass flow rate and the total mass flow rate, $P_{\mathrm{s}}$ is the saturation pressure, $P_{\text {cri }}$ is the critical pressure, $h_{10}$ is the convective heat transfer coefficient for liquid flow of total mass flow rate, $q$ is the heat flux, $G_{t}$ is the total mass flow rate, $L$ is the latent heat, and $X_{\mathrm{tt}}$ is the Lockhart-Martinelli parameter.

Change of mass flow rates of vapor and liquid in $j$ element from $i$ node to $(i+1)$ node are calculated as follows.

$$
\begin{gathered}
G_{v j i+1}+G_{v j i}=Q_{j} / L \\
G_{l j i+1}+G_{l j i}=-Q_{j} / L
\end{gathered}
$$

Pressure difference between both sides of $j$ element is calculated as follows when flow direction is from $i$ node to $(i+1)$ node.

$$
P_{i+1}-P_{i}=\Delta P_{f}-\left(1-\alpha_{v}\right) \rho_{l} g \Delta z_{j}
$$

where, $\Delta P_{\mathrm{f}}$ is the two-phase flow friction pressure drop for the horizontal tube, which was calculated with the correlation of Lockhart and Martinelli [16] using the average mass flow rates of vapor and liquid in the element, the liquid density $\rho_{\mathrm{l}}$, the gravitational acceleration $g$, the average void fraction $\alpha_{\mathrm{v}}$, and the change of vertical height $\Delta z_{\mathrm{j}}$. We did not include the change of dynamic pressure caused by phase change because it was less than the friction pressure drop $\Delta P_{\mathrm{f}}$.

Mass balance equations of vapor and liquid flow at $i$ node are calculated as follows.

$$
\begin{gathered}
\sum_{j} G_{v j i}=0 \\
\sum_{j} G_{l j i}=0
\end{gathered}
$$

The governing equations were numerically solved using an explicit iteration technique of finite difference method. Programming language was FORTRAN. In this work, thermal conductance of the loop heat pipe with multiple evaporators and condensers was defined as that the maximum heat flux in the evaporators divided by the maximum temperature difference of the evaporator-wall and the condenser-wall.

\section{Analytical Results}

\subsection{Thermosyphon-Type Loop Heat Pipe}

Thermal performance of the thermosyphon-type vertical loop heat pipe with two evaporators and two condensers, shown in Fig. 1, was calculated. The calculation conditions were the same as the experimental conditions. Inner diameter of the tube was $4.4 \mathrm{~mm}$. Length of the evaporator, condenser, vertical transport line, and horizontal transport line was 1.1, 0.4, 0.2, and $0.1 \mathrm{~m}$. Heating rate of both evaporators was examined for three cases: 350/130 W, $240 / 240 \mathrm{~W}$, and $200 / 200 \mathrm{~W}$ for the left/right evaporators. An air cooled heat exchanger was placed outside of the condenser. The outside forced 
convective heat transfer coefficient including the fin efficiency was $245 \mathrm{~W} / \mathrm{m}^{2} \mathrm{~K}$ expressed for the inside heat transfer area. Cooling air temperature was $21^{\circ} \mathrm{C}$. There was a thermal insulator $20 \mathrm{~mm}$ thick outside the transport line. The natural convective heat transfer coefficient outside of the thermal insulator including thermal conduction conductance in the thermal insulator was $29 \mathrm{~W} / \mathrm{m}^{2} \mathrm{~K}$ expressed for the inside heat transfer area. The working fluid was saturated water. Local heat flux, vapor and liquid flow rates, flow quality, pressure distribution, and temperature distribution were calculated.

Calculation results of vapor and liquid flow rates and the heat transfer rate at each element are shown in Fig. 3 for the case of heating rate of both evaporators 350/130 W. Pressure and temperature distributions are given in Figs. 4 and 5 , where $\left(P-P_{\mathrm{s}}\right)$ is the pressure difference from the saturation pressure $P_{\mathrm{s}}$ of the working fluid, $\left(T_{\mathrm{w}}-T_{\mathrm{s}}\right)$ is the temperature difference from the saturation temperature $T_{\mathrm{s}}$, and $z$ is the height. As the heating rate of the left evaporator was higher than that of the right, and the flow rate was in the flooding condition, the liquid flew upward in the left evaporator, flew downward in the right evaporator, and flew to the left through the lower horizontal transport line. Condensed liquid in the left condenser transferred to the right vertical line through the center horizontal transport line. Pressure and temperature distributions of the left and right vertical lines were almost the same. The calculation results showed that the thermal conductance of the heat pipe was $2,400 \mathrm{~W} / \mathrm{m}^{2} \mathrm{~K}$.

When the heating rate of both evaporators was 240/240 W, both evaporators were in the flooding condition and dryout occurred in the evaporators because liquid was not returned to them. In that case, a third vertical transport line of liquid from the condenser to the lower portion of the evaporator was necessary to operate the loop heat pipe properly.

Fig. 6 shows the calculation results of the vapor and liquid flow rates for the case of heating rate of both evaporators 200/200 W. As the heating rate of both

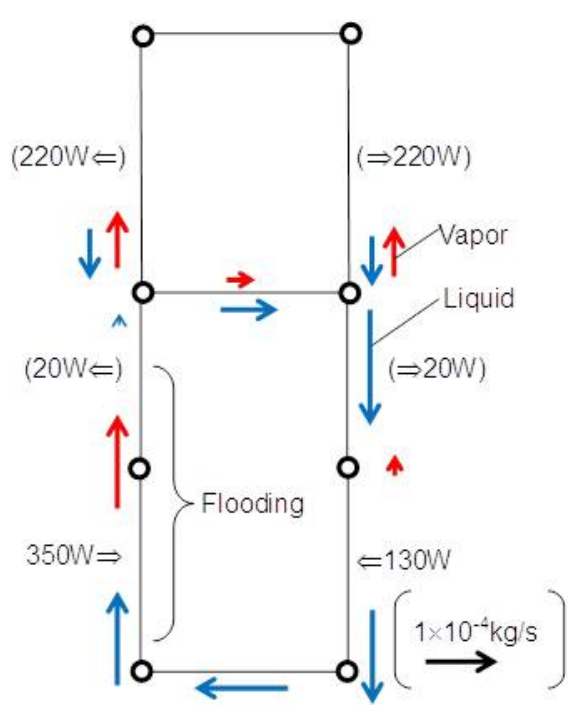

Fig. 3 Vapor and liquid flow rates and heat transfer rate for heating rate of evaporators $350 / 130 \mathrm{~W}$.

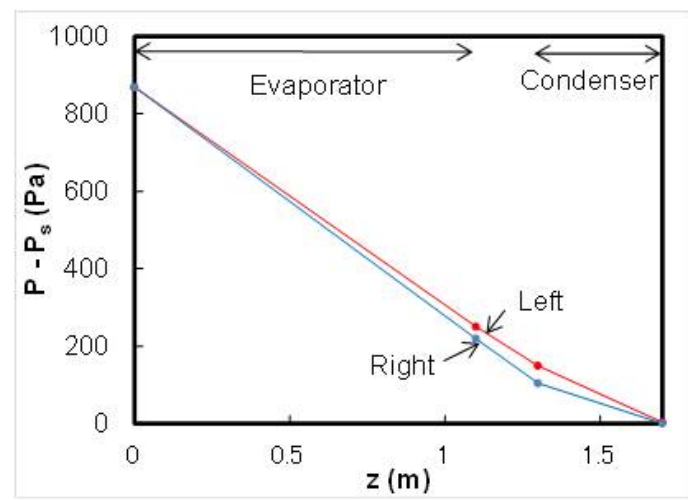

Fig. 4 Pressure distribution for heating rate of evaporators 350/130 W.

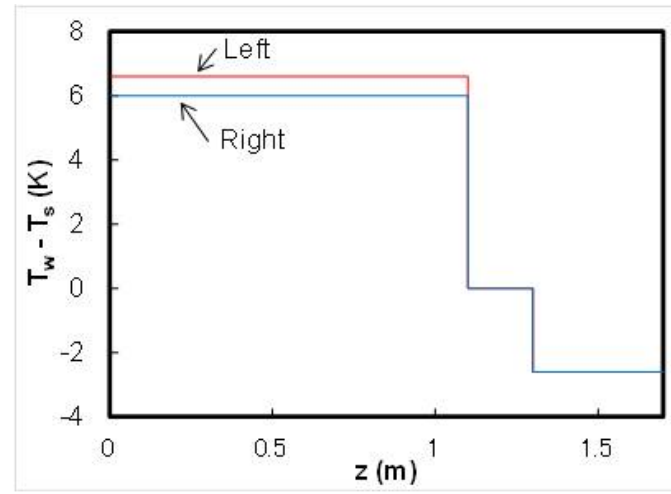

Fig. 5 Temperature distribution for heating rate of evaporators 350/130 W.

evaporators was the same value, vapor and liquid flew just like a single tube heat pipe with one evaporator and one condenser. Thermal conductance of the heat pipe was $1,600 \mathrm{~W} / \mathrm{m}^{2} \mathrm{~K}$. 


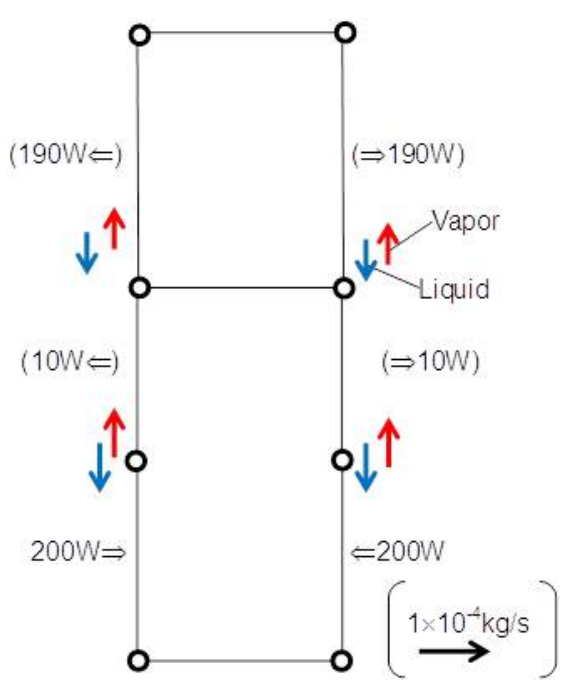

Fig. 6 Vapor and liquid flow rates and heat transfer rate for heating rate of evaporators $200 / 200 \mathrm{~W}$.

From these results, we found that the vapor and liquid flow rates in the loop heat pipe and the thermal conductance of the heat pipe changed significantly depending on the distribution ratio of the heating rate of multiple evaporators. In other words the flow rates and thermal performance of the loop heat pipes with multiple evaporators could be controlled easily, and the loop heat pipes with multiple evaporators had the advantage of design flexibility for cooling systems of many heating devices.

\subsection{Capillary-Pump-Type Loop Heat Pipe}

Thermal performance of the capillary-pump-type horizontal loop heat pipe with two evaporators and two condensers was calculated. In this case, another transport line of liquid from the condenser to the lower portion of the evaporator was added to the loop shown in Fig. 1. Condensed liquid returned to the evaporator by the capillary force in a wick in the added transport line. The calculation conditions were similar to those of the thermosyphon-type loop heat pipe. Heating rate of the left and right evaporators was 240/90 W.

Calculation results of the vapor and liquid flow rates and heat transfer rate at each element are shown in Fig. 7. The results show that the thermal conductance of the heat pipe was $1,900 \mathrm{~W} / \mathrm{m}^{2} \mathrm{~K}$.

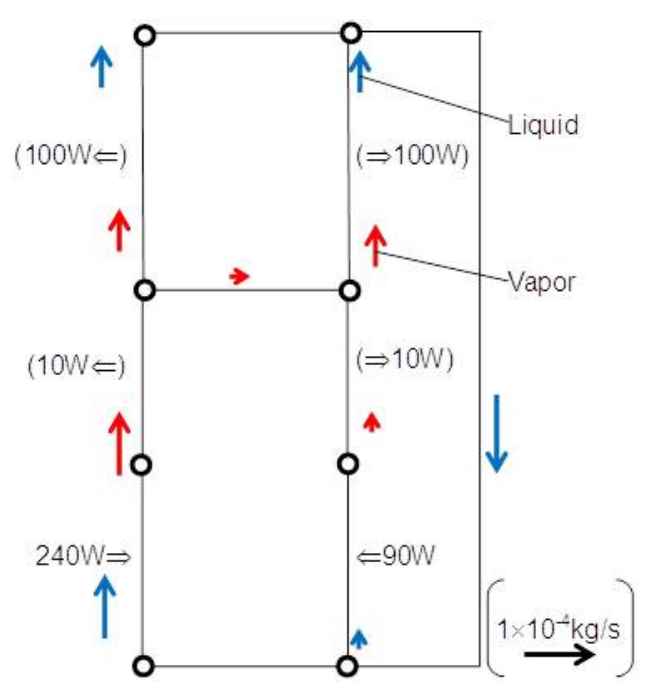

Fig. 7 Vapor and liquid flow rates and heat transfer rate for capillary-pump-type loop heat pipe.

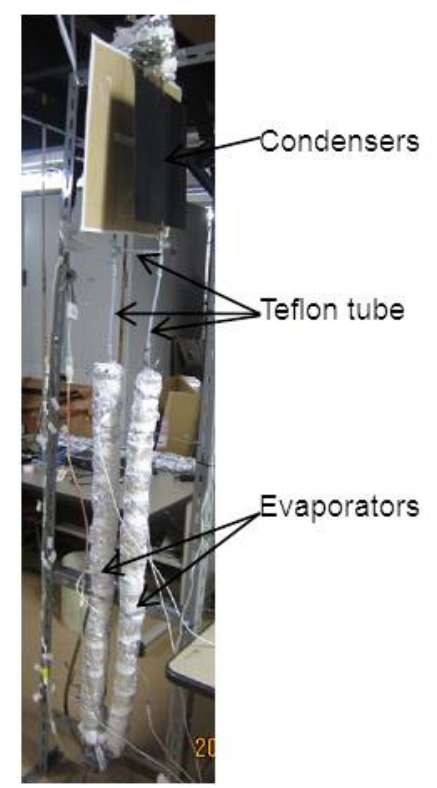

Fig. 8 Photograph of experimental apparatus.

\section{Experiments}

Thermal performance of the thermosyphon-type vertical loop heat pipe with two evaporators and two condensers, shown in Fig. 1, was experimentally examined. A photograph of our experimental apparatus is shown in Fig. 8. Experimental conditions were similar to those explained in the analytical section. The heat pipe was a copper tube with a 6 mm-outside diameter and $4.4 \mathrm{~mm}$-inside diameter. Semi-transparent Teflon tube was used as the center vertical and horizontal transport lines to see the flow 
pattern in the tube. The outside of the copper tube was covered with a rock-wool thermal insulator $20 \mathrm{~mm}$ thick. Flexible heaters were attached to both evaporators, and the heating rate of both heaters was controlled. Copper cooling plates were soldered to the condensers. The cooling rate of the condensers was controlled so that the saturation temperature of the working fluid could be adjusted to near $100{ }^{\circ} \mathrm{C}$ by changing the flow velocity of the cooling air. The working fluid was saturated water. The T-type thermocouples were soldered at 23 positions of the heat pipe, and the temperatures at steady state were measured. The saturation temperature was assumed to be the same value as the wall temperature at the upper horizontal transport line of the heat pipe, and it was measured by the thermocouples. Accuracy of temperature measurement with thermocouples was $\pm 1.0^{\circ} \mathrm{C}$ and the relative error was $\pm 0.1 \%$.

When the heating rate of the left and right evaporators was 350/130 $\mathrm{W}$, the experimental result of the average temperature of the left evaporator tube was $109^{\circ} \mathrm{C}$, that of the right evaporator was $105^{\circ} \mathrm{C}$, that of the condenser was $98^{\circ} \mathrm{C}$, and the saturation temperature of the working fluid was $104^{\circ} \mathrm{C}$. Flow direction pattern was the same as that in Fig. 3. Thermal conductance of the heat pipe was 2,200 $\mathrm{W} / \mathrm{m}^{2} \mathrm{~K}$. The flow direction and thermal conductance of the heat pipe were in agreement with the analytical results discussed in the previous section. When heating rates of multiple evaporators were not same, thermal conductance of the heat pipe was large similar to the calculation results. We found that the lumped network model analysis was accurate, useful, and preferable for the practical design of a loop heat pipe with multiple evaporators.

\section{Conclusions}

Thermal performance of a loop heat pipe with two evaporators and two condensers was examined using a lumped network model analysis and experiments. The following results were obtained:
(1) The vapor and liquid flow rates in the loop heat pipe and thermal conductance of the heat pipe with multiple evaporators changed significantly depending on the distribution ratio of the heating rate of multiple evaporators. When heating rates of multiple evaporators were not same, thermal conductance of the heat pipe was large;

(2) Experimental results of flow direction and thermal conductance of the heat pipe agreed with the analytical results. The lumped network model analysis was shown to be accurate, useful, and preferable for the practical design of a loop heat pipe with multiple evaporators.

\section{Acknowledgments}

Authors thank to Mr. Tomohisa Kawaguchi of Kobe University for helping experiment.

\section{References}

[1] Toyoda, H., and Kondo, Y. 2013. “Heat Transfer Performance of Loop Thermosyphon Using Enhanced Boiling and Condensation Surfaces." Transaction on Control and Mechanical Systems 2 (12): 432-5.

[2] Hirasawa, S., Sato, S., Kawanami, T., and Shirai, K. 2013. "Transient Heat Transfer Characteristics of Inclined Loop-Thermosypn-Type Heat Pipe for Solar Collector with Changing Input Solar Heat Flux.” Proceedings of the 17th International Heat Pipe Conference, Paper-No.42.

[3] Ku, J., Ottenstein, L., Douglas, D., and Hoang, T. 2012. "Technology Overview of a Multi-evaporator Miniature Loop Heat Pipe for Spacecraft Applications.” Journal of Spacecraft and Rockets 49 (6): 999-1007.

[4] Ku, J., Ottenstein, L., Douglas, D., and Hoang, T. 2012. "Validation Design for a Multi-evaporator Miniature Loop Heat Pipe for Spacecraft Applications.” Journal of Spacecraft and Rockets 49 (6): 1008-18.

[5] Kaya, T., and John Goldak, J. 2006. "Numerical Analysis of Heat and Mass Transfer in the Capillary Structure of a Loop Heat Pipe.” International Journal of Heat and Mass Transfer 49: 3211-20.

[6] Figus, C., Bray, Y. L., Bories, S., and Prat, M. 1999. "Heat and Mass Transfer with Phase Change in a Porous Structure Partially Heated Continuum Model and Pore Network Simulations.” International Journal of Heat and Mass Transfer 42: 2557-69. 
[7] Jesuthasan, N., and Baliga, B. R. 2009. "Steady-State Segmented Thermofluid Network Simulations of a Loop Heat Pipe Operating with Four Different Working Fluids.” Proceedings of ASME 2009 Heat Transfer Summer Conference, HT2009-88411.

[8] Kaviany, M. 2011. Essentials of Heat Transfer: Principles, Materials, and Applications. New York: Cambridge University Press.

[9] Watanabe, T., and Hirasawa, S. 2014. "Network Model Analysis of Poly-Silicon Film Deposition on Wafers in CVD Reactor." Journal of Chemical Science and Technology 3 (1): 1-7.

[10] Bai, L., Lin, G., and Wen, D. 2010. "Modeling and Analysis of Startup of a Loop Heat Pipe.” Applied Thermal Engineering 30: 2778-87.

[11] Goncharov, K., Golovin, O., and Kolesnikov, V. 2000. "Loop Heat Pipe with Several Evaporators." SAE
Technical Paper 2000-01-2407.

[12] Nagano, H., and Ku, J. 2007. "Capillary Limit of a Multiple-evaporator and Multiple-condenser Miniature Loop Heat Pipe.” Journal of Thermophysics and Heat Transfer 21 (4): 694-701.

[13] Wallis, G. B. 1969. One-Dimensional Two-Phase Flow. New York: McGraw-Hill.

[14] Shah, M. M. 1979. “A General Correlation for Heat Transfer during Film Condensation inside Pipes.” International Journal of Heat and Mass Transfer 22 (4): 547-56.

[15] Schrock, V. E., and Grossman, L. M. 1962. "Forced Convection Boiling in Tubes.” Nuclear Science and Engineering 12 (4): 474-81.

[16] Lockhart, R. W., and Martinelli, R. C. 1949. "Proposed Correlation of Data for Isothermal Two-Phase, Two-Component Flow in Pipes.” Chemical Engineering Progress 45 (1): 39-48. 